Thélème. Revista Complutense de Estudios Franceses ISSN-e: 1989-8193

http://dx.doi.org/10.5209/THEL.60485

\title{
El tratamiento de Madame, les filles y el ethos discursivo de Maupassant en Le Plaisir de Max Ophuls
}

\author{
Alfredo Segura Tornero ${ }^{1}$
}

Recibido: 30 de mayo de 2018 / Aceptado: 26 de julio de 2018

Resumen. Max Ophuls propone en Le Plaisir una transposición de tres relatos de Maupassant. La representación discursiva del filme cuenta con numerosos puntos convergentes, aunque es necesario resaltar que Ophuls favorece un reflejo menos realista y naturalista de los personajes, en particular de las prostitutas. Las divergencias más significativas se sitúan en el nivel enunciativo con la inclusión del ethos discursivo de Maupassant, convertido en personaje. La manera de abordar el punto de vista es un balbuceo del cine de voyeurismo cuya esencia es el movimiento. En este sentido, cabe preguntarse si el narrador Maupassant de Max Ophuls una anticipación a la cámara de la Nouvelle Vague.

Palabras clave: Max Ophuls, Guy de Maupassant, Madame Tellier, Le Plaisir, ethos discursivo, punto de vista.

[fr] Le traitement de Madame, les filles et l'ethos discursif de Maupassant dans Le Plaisir de Max Ophuls

Résumé. Max Ophuls propose dans Le Plaisir une adaptation de trois récits de Maupassant. La représentation discursive du film possède plusieurs points convergents, même s'il faut également souligner qu'Ophuls privilégie une présentation moins réaliste et naturaliste des personnages, essentiellement des prostitués au détriment d'éléments plus scabreux. Les écarts les plus significatifs se situent au niveau énonciatif où le metteur en scène introduit l'ethos discursif de Maupassant, faisant de lui un personnage. La manière d'aborder le point de vue chez Max Ophuls est un balbutiement dans le cinéma de voyeurisme dont l'essence semble être le mouvement. En ce sens, nous pourrions nous demander si le narrateur Maupassant chez Max Ophuls serait en quelque sorte une anticipation de la caméra de la Nouvelle Vague.

Mots clés : Max Ophuls, Guy de Maupassant, Madame Tellier, Le Plaisir, ethos discursif, point de vue.

[en] A character analysis of Madame, the filles and the ethos of the speech in Le Plaisir by Max Ophuls

Abstract. In Le Plaisir, Max Ophuls proposes an adaptation of three texts by Guy de Maupassant.
Although the discursive representation in the film is similar to the literary texts in some respects, Ophuls
presents a less realistic and naturalistic portrait of the characters, in particular of the prostitutes. The
most important divergences between the film and the literary texts is the inclusion of an intermediate
narrator, Maupassant, in the film. In this sense, Ophuls' point of view could be considered a form

Universidad de Castilla-La Mancha

alfredo.Segura@uclm.es 
of cinematic voyeurism, based in movement. In consequence, the narrator Maupassant could also be perceived as an anticipation of Nouvelle Vague's camera.

Keywords: Max Ophuls, Guy de Maupassant, Le Plaisir Madame Tellier, ethos of the speech, point of view.

Sumario: 0. El ethos discursivo de Maupassant. 1. Madame Tellier. 2. Les filles. 3. Conclusión.

Cómo citar: Segura Tornero, A. (2018). "El tratamiento de Madame, les filles y el ethos discursivo de Maupassant en Le Plaisir de Max Ophuls". Thélème. Revista Complutense de Estudios Franceses, Vol. 33, Núm. 2: 305-318.

La novela del siglo XIX había construido un nuevo narrador omnisciente, más rico que los precedentes y cuya subjetividad a veces se confundía en breves pinceladas con la de los personajes de sus relatos. Javier del Prado, Juan Bravo y María Dolores Picazo, en un exhaustivo análisis de la modernidad literaria basada en la emergencia del yo, afirmaban:

La crítica moderna nos ha demostrado que el texto realista y naturalista es el que mejor se presta a un estudio temático, relativo a la ensoñación del yo en la escritura, y que, paradójicamente, no hay texto más subjetivo que el producido por el narrador realista (Del Prado, Bravo y Picazo, 1994: 266).

Los tres autores citados ${ }^{2}$ muestran cómo el narrador llamado omnisciente necesita de una revisión y matización importante. Este tipo de narrador tiene que luchar contra la presencia de su yo en función de la perspectiva enunciativa vista en su complejidad: identidad del sujeto narrador, relación de éste con el héroe, fuentes de información, punto de vista respecto a los personajes, estructura de la coordenada temporal -analepsis y prolepsis que atestiguan su omnipresencia, etc.-.

Si bien el tema de las prostitutas ha sido ampliamente tratado en la obra de Maupassant $^{3}$, no se ha profundizado en las adaptaciones fílmicas de narrativa naturalista. Nos parece, así pues, de interés centrar específicamente la temática propuesta al abordar un estudio comparativo del tratamiento de los personajes principales en la transposición de Max Ophuls. Tras el narrador en la película, el ethos discursivo de Maupassant, y el análisis de su tratamiento en las dos primeras secuencias, se procederá a un cotejo con la obra literaria de las protagonistas.

\section{El ethos ${ }^{4}$ discursivo de Maupassant}

Max Ophuls se encuentra en 1951 en una situación especial de su carrera cuando se materializa el proyecto de llevar a la gran pantalla dos cuentos y una novela corta de

2 Las tesis novedosas de estos tres autores, a mitad de los años 90, se acercan a teorías narratológicas muy recientes, especialmente en lo referente a la perspectiva enunciativa y la multiplicidad de voces en la novela a través de la constelación de emergencias del yo, como las de Maingueneau (2004) o Jean-Michel Adam (2008). Coinciden asimismo en el estudio principalmente de los mismos autores como Flaubert, Zola, Stendhal y Proust.

3 Véanse entre otros: Adler (1990), Bury (1994), Dahhan (1996), Corbin (1980), Lutanie (1993), Parent-Duchâtelet (1981), Mourier-Casile (1991).

4 Ethos entendido, según Maingueneau (2004) y Meizoz (2009), dentro de la scène d'énonciation donde cabrían la posture -imagen exterior del escritor -, l'image d'auteur-formada por la información que del autor conoce el lector -y ethos -noción puramente discursiva, construida a través del discurso literario. 
Maupassant ${ }^{5}$. La película Les Désemaparés cuya salida en 1950 en las pantallas americanas había resultado un fracaso, y el éxito el mismo año de La Ronde en Europa fueron determinantes a la de tomar la decisión de seguir trabajando al menos un tiempo en el viejo continente. Hacía ya dieciocho meses que había abandonado los EEUU para filmar en suelo europeo una película americana que nunca llegó a realizarse, La Duchesse de Langeais, una adaptación de Balzac, con nada menos que Greta Garbo encabezando el reparto.

A la mitad del mes de marzo de 1951 -apenas seis meses después del estreno de La Ronde- la prensa internacional anuncia para el 15 de mayo el comienzo del rodaje de Le Plaisir, producido por una nueva compañía de la que nadie sabe nada, la Société technique d'études et de réalisations artistiques (Stéra films). El equipo técnico estará formado por dos de los más fieles colaboradores de Max Ophuls, el adaptador Jacques Natanson y el decorador Jean d'Eaubonne. El film tendrá también la suerte de contar con el trabajo de Jean Valère -amigo de Marcel Ophuls quien lo había recomendado fervientemente a su padre-, uno de los mejores asistentes de realización del momento. El jefe operador será Christian Matras cuya participación en el último largometraje del alemán había satisfecho todas las expectativas del director.

El productor, Denis Kieffer, tenía la clara ambición de renovar el éxito cosechado en $\mathrm{La}$ Ronde reuniendo varios actores de prestigio en una película con tres partes. No se sabe quién de los dos, productor o director, propuso a Maupassant, pero lo que sí sabemos con seguridad, así lo manifiesta él mismo en sus notas autobiográficas redactadas en Hollywood ${ }^{6}$, es que Ophuls desde 1945 tenía la intención de adaptar al autor de "La Maison Tellier":

J'ai toujours été attiré par l'univers des souteneurs et des filles -cet univers où reposent tant de soldats inconnus de l'amour, qui forme la base honteuse et pourtant réelle de la morale bourgeoise- j'ai souvent rêvé de faire un film consacré à ce sujet. Un film dont le scénario serait d'un Maupassant moderne. Par endroits, quelques instants de ce rêve apparaissent comme en filigrane dans "Sans lendemain", du moins je l'espère. Mais ce n'est qu'un timide début.... (Ophuls, 1962: 30).

La intención de Ophuls era que el propio Maupassant narrara las tres historias, un autor que sin cuerpo dialogaría con un cineasta con dificultades para encontrar un tema. El guión original ${ }^{7}$ situaría el encuentro entre el cineasta y el escritor delante de la Biblioteca Nacional de París. Los dos irían en coche hasta un campo brumoso al borde del Sena donde el escritor le propondría la historia de Sur l'eau, un cuento macabro con aspectos fantásticos. El cineasta le respondería que no era una historia que se pudiera rodar pidiéndole algo más alegre donde hubiera movimiento, ruido, baile. La voz de Maupassant sugeriría entonces "Le Masque", seguida de "La Maison Tellier" y para terminar "La Femme de Paul". Esta idea del dialogo inicial se mantuvo hasta el último momento y sólo fue descartada cuando ya se había desecha-

Seguimos a Berthomé (1997) para la información relativa al desarrollo de producción del film.

En 1941 emigra a los EEUU donde no encuentra trabajo. Aprovecha este tiempo de inactividad forzada para redactar sus Mémoires, libro de recuerdos publicado después de su muerte.

7 Según Berthomé (1997: 19) existen varios ejemplares del guion original, entre ellos uno anotado por Paule Converset, la script-girl de la película, en los fondos de los archivos de la BIFI en París. Su cotejo con el film sería uno de los puntos de importancia para la comprensión de todo el proceso de la transposición. 
do el rodaje de "La Femme de Paul". El guion de "Le Modèle" comienza, sin embargo, con un intercambio entre la voz de Maupassant y la de un cronista parisino al que dice prestar a menudo su voz. La aparición de este cronista, inexistente en los otros cuentos, parece explicarse por la necesidad económica de hacer desaparecer algunas escenas costosas, entre ellas la de Maupassant con el cineasta y su viaje a la búsqueda de una historia. Sea como fuere, la presencia de un cronista en "La Maison Tellier" introduce un narrador nuevo y complementario, distinto al del rodaje de los otros dos.

Guy de Maupassant, el escritor esta vez, al reunir los cuentos para publicarlos no pensó ni tenía en mente la unión entre ellos, en parte porque los publicaba muchos en la prensa separadamente antes de lanzarse a su publicación conjunta en un volumen. Por su parte, en el film que nos ocupa, la no justificación de la ligazón de los tres cuentos que lo componen formando un todo produciría irremediablemente un efecto de desorientación al espectador. La inclusión de un fundido en negro al inicio de cada historia, y la voz del narrador Maupassant que presenta la siguiente historia, evita su total separación. Estamos frente, ante todo, a una convención artística convertida en necesidad en el cine a la que se acogió Max Ophuls para pensar en una transición entre "Le Masque" y "La Maison Tellier", al igual que también entre ésta y "Le Modèle". En la nueva y muy reciente versión masterizada de Gaumont (2009) ${ }^{8}$ el tiempo se congela en el primer fotograma en negro, no corriendo el reloj. Una prueba más de que la voz en off del ethos Maupassant narrador, aun formando parte del conjunto, no se incluye en la historia. Se debería tratar como un paratexto sirviendo como elemento de unión entre dos historias aparentemente sin muchas concomitancias, salvo el tema del placer tomado como goce vital que destruye o cataliza el equilibrio individual, familiar y hasta social. Funciona, en el caso, por ejemplo, en el inicio de la transposición de "La Maison Tellier" como una captatio benevolentiae anclando primero el tono: Voulez-vous une chose plus joyeuse?; de alguna manera a modo de introducción del género alejado de Maupassant escritor, un conte de fées pour grandes personnes; y el lugar, en Normandie, dans une petite ville, un petit port, un quartier pas précisément résidentiel [16'06"] ${ }^{9}$. La idea original, pues, se ve transformada en el resultado final con la incorporación del ethos del personaje Maupassant que añade una doble narración, ausente esta en los cuentos originales. Asimismo, en la novela nada parece indicar que el narrador omnisciente tenga un límite a su conocimiento de la historia o de su universo, no así en la película, como por ejemplo en la primera secuencia.

La novela y la película debutan ambas con una secuencia narrativa que podríamos denominar de escasa narratividad puesto que contiene los elementos mínimos para articularse como narración sin adornos ni complejidades, secuencia en la que el imperfecto de indicativo será la tónica dominante ${ }^{10}$. El film comienza con un planosecuencia muy llamativo. La cámara apunta en picado hacia los edificios a la que le sigue una panorámica vertical descendente. El ángulo de las tomas de esa primera

8 Edición consagrada enteramente a la obra de Max Opuls que recoge: Le Plaisir, Madame de..., Lola Montes y La Ronde. Interesante la inclusión del documental L'histoire du film del hijo de Max, Marcel Ophuls, donde da claves para la interpretación de cada film comentando su génesis y realización.

9 Seguimos para el minutaje aquí y en adelante la ya citada edición de la película, Ophuls, M., (1952) Le Plaisir, París, Gaumont. Edición masterizada 2009.

10 Es necesario recordar que la mayor parte del texto del guion, tanto narración como diálogos, es una reproducción del texto literario del autor normando. 
panorámica rompe nuestra visión del suelo plano provisto de líneas verticales y horizontales. La suma del contrapicado desde la escalera con líneas poco naturales de la calle y casas produce el mismo efecto que el travelling primero de aproximación hacia la casa, al mismo tiempo que la cámara acompaña a los clientes de la maison close. El punto de vista sería el de uno de los clientes que acompañara a los que llegan tarde, dentro de la escena, por tanto. La secuencia termina al cerrar la puerta Madame, trop tard, dejando fuera a los clientes tardíos y a la propia cámara que los acompañaba. En ningún momento en la película el punto de vista se adentra en la casa. Y ese será sin ningún lugar a dudas uno de los puntos fundamentales de divergencia con el texto literario. El recurso del "voyeur" acompaña el transcurrir de los personajes y se distancia en prácticamente todas las escenas.

\section{Madame Tellier}

Durante su vida, Guy de Maupassant fue un habitué de los burdeles. Nunca lo ocultó, y llegó hasta vanagloriarse de haber contraído la sífilis de la que presumiblemente moriría a los 43 años. El 2 de marzo de 1887 envía una carta a su amigo Robert Pinchon anunciándole que ha contraído la sífilis: "J'ai la vérole! Enfin! La vraie! [...] et j'en suis fier, morbleu, et je méprise par-dessus tout les bourgeois" " Sincera o no esta manifestación, provocación o no, nos sitúa con claridad en la ambivalencia de su amor por el mundo de los lupanares y su desprecio de la sociedad burguesa. "Boule de suif" (1880) y "La Maison Tellier" le dan la celebridad; no es casualidad si esas dos novelas cortas tratan de filles ${ }^{12}$. En la primera, el patriotismo de una prostituta estará por encima del de un grupo de burgueses y un idealista durante la Guerra Franco-Prusiana; en la segunda, el cierre un sábado por la noche del lieu de rejouissance rompe la paz social dejando al descubierto el verdadero comportamiento mezquino que los burgueses tienen entre ellos. Si los dos comparten un retrato positivo de la prostitución, implican también una crítica más o menos feroz de la sociedad burguesa de la Troisième République. Para Maupassant su carrera de literato comienza con una historia cuya protagonista es una prostituta, y es con una historia de una prostituta que todo termina, "Les Tombales", último cuento publicado en Gil Blas, el 9 de enero de 1891. El escritor mismo la añadirá a la reedición de "La Maison Tellier".

La segunda secuencia del film, de carácter descriptivo, presenta a Madame junto a sus trabajadoras. Su ordenación no es casual sino que corresponde al deseo de alabar las virtudes de las dos por igual, casa y Madame, consagrando alternativamente los párrafos a sus descripciones. Con relación a la adaptación se optó por la descripción de forma separada y, sin embargo, algo nos parece que se mantiene igual. Hemos visto en la primera secuencia introductoria la utilización del plano secuencia como recurso de alargamiento temporal. Esta vez Max Ophuls dedicará un plano a

11 Desaparecida la carta durante la Segunda Guerra Mundial, fue publicada primero solo en parte por Jacques Suffel (1973) como Lettre 62, para posteriormente serlo en su totalidad por Anne-Marie Springer (2006: 132135), con nota explicativa del Luc Montagner.

12 Noëlle Benhamou (1997: 45) lo describe así: "Le personnage littéraire de la 'fille' touche à différentes sphères. Il est lié à des milieux aussi divers que le monde de l'art, de la presse, du théâtre, de la peinture et de la finance. Est considérée comme "fille" toute femme adultère et comme "prostituée" toute femme célibataire dont le principal revenu provient du commerce de ses charmes". 
cada personaje que describa. De esta forma el párrafo en el texto literario se convierte en unidad de corte en el lenguaje cinematográfico también. No son unidades de análisis textual, aunque esta vez son utilizadas con este fin, dando un ritmo ordenado a la prosa y ayudando de forma cadenciosa a la progresión. El primer plano-secuencia es la presentación de Madame que comienza con un travelling vertical hasta el segundo piso donde se traslada por medio de un travelling lateral de aproximación cuando aparece Madame en las ventanas hasta que llega a su habitación que reconocemos por el retrato de su marido fallecido. El movimiento es de izquierda a derecha en el sentido de nuestra lectura, la narración y el relato -entendidos en términos de Genette (1972), narración como acto de contar y relato como acciones que se suceden- avanzan sin contratiempos, el tiempo fluye desde el pasado hacia el presente. Una vez más la presencia del imperfecto es omnipresente, acompañando a los travellings. Las excursionistas en el momento de la ida de su viaje lo harán con el movimiento de las imágenes en el sentido de la lectura, de izquierda a derecha, por el contrario la vuelta o cuando haya un contratiempo de derecha a izquierda, en un movimiento de lectura antinatural. Texto literario y transposición irán de la mano en esta bella presentación de Madame. Sobresale el grado de profesionalidad de la dueña Une paix jalouse, mais rarement troublée, régnait entre ces cinq femmes, grâce à la sagesse conciliante de Madame; su carácter et à son intarissable bonne humeur; su amabilidad Enfin elle avait l'âme délicate, et, (...) traitant ses femmes en amies; y su profesionalidad Madame, issue d'une bonne famille de paysans du département de l'Eure, avait accepté cette profession absolument comme elle serait devenue modiste ou lingère [16'20'-16'38'].

Con respecto al punto de vista, el narrador es el mismo que en la primera secuencia. No obstante, se introduce un cambio ya que el narrador se distancia del receptor. Madame y los inquilinos de la casa son percibidos de forma idéntica, guardando la misma naturalidad que con la que los clientes van simplement todas las noches. Esto es, los travellings que siguen a Madame muestran cómo cierra las ventanas de una maison close que quedan tan abiertas como antes gracias a que las persianas de láminas permiten ver todo en su interior. El contraste entre el narrador en la película que se esconde siempre y la maison close no lo es tanto. Hecho que contribuye a dar naturalidad al comportamiento de los de dentro pero también para dar cuenta de que si para los clientes no había prejuicios, para los inquilinos de la casa tampoco. En resumen, todos los personajes para las dos versiones a excepción del narrador en la cinematográfica comparten ese simplement. Por otra parte, si el narrador observa desde cierta la distancia la acción, ¿puede ser visto por los personajes? La secuencia de la descripción de la casa comienza: La maison avait deux entrées. A l'encoignure, une sorte de café borgne s'ouvrait [17'50'-17'57']. Pues bien, la película comienza justo con el punto de vista en la posición de la cámara en la encoignure de la casa. Y este lugar no es otro que el punto de fuga, punto que desde dentro de la casa se ve difícilmente. El narrador no quiere ser visto y se coloca en el lugar donde resulta más difícil percibirlo, es decir en la proyección de la encoignure. El narrador y, por ende, los espectadores tienen la mejor panorámica, desde el interior ocurre lo contrario. La cámara está dentro de la escena pero se las arregla para que los personajes no la perciban. Prueba evidente de que el narrador está dentro de la historia. Si éste es omnisciente, debe matizarse su grado.

La secuencia enteramente dedicada a Madame tiene como continuación natural la asociación del personal de la casa. En la novela, se alternan los párrafos en una mis- 
ma secuencia lo que no separa tanto a Madame de su personal. Esta separación en la película puede venir determinada por el texto literario donde se especifica claramente que Madame piensa que sus empleadas y ella no son $d u$ même panier. Asistimos a una verdadera profesionalización de su puesto, se presenta como persona de moral intachable, teniendo en cuenta que para la campiña normanda no existen juicios de valor negativos para la regencia de un burdel. Madame es una verdadera mujer de negocios; la mejor prueba es que es decisiva para la progresión de los hechos en la novela allí donde interviene. Tomará siempre, no únicamente la decisión correcta para la feliz resolución del conflicto, sino que mostrará una firmeza en sus decisiones, envidia del mejor hombre de negocios. Esta eficacia será la base para la pacificación y el buen entendimiento de los ciudadanos. Queda por decir que el valor afectivo que se le da es diferente del tratamiento de los demás personajes en esta secuencia. La distancia emocional de Madame, la planificación, es más corta que la de los inquilinos. Al cerrar la ventana la distancia emocional crece gracias a planos cortos y medios cortos. Se prepara así una mejor identificación con el personaje que ocurrirá conforme avance la historia. La asociación de la casa a un negocio respetable parece inevitable, consecuencia en buena parte porque la gerente lo es. Los habitués respetarán tanto a Madame como a la casa que representa.

De todos los personajes que figuran en la novela, las filles y Madame tienen un papel predominante. No sólo porque son los únicos que aparecen en todas las secuencias sino porque ellas son las que funcionan como verdaderas catalizadoras en una sociedad que las estigmatiza por un lado, y las considera de utilidad pública por otra. Sería difícil señalar a una sola como protagonista; todas en su papel contribuyen al avance de la diégesis, fundiéndose en ella. Como en la vida real, ellas no poseen un papel principal, aseguran con su trabajo el equilibrio necesario. De las dos, Max Ophuls toma sin apenas variaciones a Madame. Todo parecía convenirle en el retrato que diseña el normando. No será, por tanto, objeto de comparación aquí, pero sí interesa su imagen para cotejarla con la de sus empleadas. De las filles la imagen es sensiblemente distinta. El director alemán, manteniendo la fidelidad, quiso idealizarlas. De alguna manera, las metió casi en el même panier con Madame, metáfora con la que la patrona marcaba y señalaba las diferencias con el resto de inquilinas. Para ello, eliminó todo rasgo de crudeza o excesiva naturalidad en su físico, carácter o comportamiento.

El personaje de Madame tenía ya en la novela de Maupassant todos los elementos que le interesaban, de ahí que los mantuviera y hasta potenciara. Era respetada: $\mathrm{Ou}$ bien on causait avec Madame, que tout le monde respectait [16'20"-16'22']. La casa representa la cara opuesta de una iglesia, a la que complementa dando el equilibrio y la normalidad a la vida de los burgueses: La maison était familiale, toute petite, peinte en jaune, à l'encoignure d'une rue derrière l'église Saint- Étienne [16'28'16'31']. Si los clientes van cada noche simplement, es porque la naturalidad reina en Madame y casa: Madame, issue d'une bonne famille de paysans du département de l'Eure, avait accepté cette profession absolument comme elle serait devenue modiste ou lingère [16'33"-16'38']. Viuda y deseada por sus clientes, no se le conoce desliz alguno, dedicando todo su esfuerzo al buen gobierno de su negocio. El respeto pasaba también por mantenerse distanciada de las tareas cotidianas encomendadas a las pensionnaires. El contrapunto se presenta como el descanso, el punto de apoyo con el que contaban sus clientes. La casa Tellier es, al fin y al cabo, de utilidad pública porque funciona para los burgueses a dos velocidades, el desahogo del cuerpo con 
unas, la catarsis espiritual con la patrona. No obstante, gracias a su capacidad de resolución de conflictos tiene un papel primordial de garante de la paz social. Ella sola es capaz de crear un ambiente distendido allí donde no lo habría. Interviene asimismo expulsando del tren al viajante que se había propasado en el túnel; distribuye los asientos en la carreta para un viaje más cómodo y equilibrado hacia la casa de su hermano; decide no entrar en la iglesia el sábado para no molestar a los querubines del coro; ordena firmemente el regreso a casa después del banquete ante la oposición de Joseph que lucha por conservar un día más a sus invitadas; negocia con María el futuro de Constance de la que promete ocuparse; soluciona con contundencia el acoso de Joseph a Rosa; y por fin en la fiesta del domingo por la noche compensa a sus clientes de su ausencia no solo con su excesiva jovialidad, también al rebajar el precio de la botella de champagne a seis francos en lugar de los de costumbre, incluso en el film insinúa a M.Tourneveau que podría ser generosa en el amor esta noche porque desea que todo el mundo sea feliz.

\section{Les filles}

Maupassant es ante todo un pintor de filles, así lo defienden Pascaline Mourier-Casile (1991: 35): "Le thème des filles -compte tenu de l'extension que Maupassant donne à ce terme- est sans doute celui qui revient le plus souvent dans ses contes et nouvelles", y Louis Forestier (1995: 37a) "Des femmes, il en est de toutes les sortes dans cette oeuvre, et l'auteur prend visiblement plaisir à les évoquer et les mettre en scène". ¿Es la visión más o menos idílica de la prostitución que se refleja en "La Maison Tellier" la que será la tónica en toda su obra? Claramente no. Todos los estudiosos están de acuerdo en que la visión que se da es de una perfecta verdad histórica, de una exactitud casi de laboratorio. El tema es omnipresente, hasta obsesivo, sin olvidar que su inclusión aseguraba el éxito editorial. Noëlle Benhamou ${ }^{13}$ :

$\mathrm{Au} \mathrm{XIX}^{\mathrm{e}}$ siècle, la prostituée est partout. Symbole de la modernité, elle a littéralement -et littérairement- envahi le roman. Tandis que s'opèrent d'importants bouleversements dans la politique et les mentalités, le personnage de la prostituée, courtisane magnifique ou fille du ruisseau, s'installe de plus en plus dans les écrits littéraires (Benhamou, 1997: 257).

¿Cuál es su imagen en Le Plaisir? El oficio de las pensionnaires estaría dentro de lo que podríamos denominar la prostitución reglamentada/reglada, que tiene su origen en la preocupación de la higiene pública. En la época del Consulat los problemas de salud pública empiezan a obsesionar a los dirigentes y médicos. La medicina de Broussais interesada en las infecciones y la fisiología pretende crear una sociedad sana y agradable (Corbin, 1980: 43) "débarrassée de ses charognes et de ses excréments". La prostituta amenaza el orden moral por la transmisión de enfermedades venéreas convirtiéndose en el símbolo de la "ordure morale qui pourrit les corps et pue"). Michel Foucault (1997: 154) nos advierte que "non seulement est une affaire laïque, mais une affaire d'Etat; mieux, une où le corps social tout entier, et presque

13 Tesis de Doctorado dirigida por Philipe Hamon y defendida en 1996 en la Université de Paris III. Es un estudio pormenorizado de los tipos distintos de prostitutas en los relatos cortos y las novelas. Se enfoca desde un método sociocrítico y psicoanalítico. 
chacun de ses individus, était appelé à se mettre en surveillance". Con el fin de protegerse contra esta plaga, la administración debe tomar medidas. Por otra parte, este mal necesario debe tolerarse para el "bon fonctionnement de l'organisme social" (Corbin 1980: 43). Se elabora la reglamentación que tiene como objetivo el control sanitario de las filles en los lugares públicos. El responsable del néo-réglementarisme es Parent-Duchâtelet que dedica trece años, de 1822 a 1835, a realizar un estudio de la prostitución y redactar su trabajo De la prostitution dans la ville de Paris. En este libro presenta una nueva visión (citado en Corbin 1982: 13): "l'humanisation du traitement des vénériens". En general, la prostitución reglada tiene su base en el mantenimiento de las prostitutas en una maison $\operatorname{clos}^{14}$, también llamada maison de tolérance porque es tolerada por el prefecto de la policía. Es conveniente que estén en este tipo de instituciones para que la prefectura, por lo general los sábados ${ }^{15}$, pueda enviar un médico a efectuar el control sanitario pertinente. En el caso de que alguna tenga una infección venérea, se le envía al hospital y así no contagiar a "les gens honnêtes". Cuando la fille no cumple es encarcelada. Por último, si desea abandonar la profesión puede elegir ir a l'établissement de repentance ou de relèvement, siguiendo el camino recto y llevando una vida austera como la de un convento. Toda esta reglamentación francesa se ocupa de este modo de aquellas que están en prostíbulos y las que están aisladas, sea en el hospital o en casas de corrección. En los cuentos de Maupassant hay tres tipos de cuentos, en tres zonas geográficas distintas, que se relacionan directamente con estos tipos de establecimientos: las prostitutas de burdeles de provincias, "La Maison Tellier", "Mademoiselle Fifi", "Une Soirée", "Les Vingt-cinq francs de la supérieure"; las que están en un barrio reservado en Marsella, "Le Port"; y las que están aisladas en París, "Le Moyen de Roger".

El burdel está compuesto por una maîtresse que regenta el establecimiento, y que cuenta con el apoyo de una sous-maîtresse. El personal está formado por varias pensionnaires que se ocupan de satisfacer a los clientes, y uno o varios garçons que ayudan en el servicio e intervienen en el caso de conflicto. Las pensionnaires se denominan también fille à numéro. Su nombre se debe a que su número debe constar en el registro de la regente del local. Cada casa lleva un número de orden ${ }^{16}$. La que trabaja sola en casa se le denominará fille à carte, porque recibe una tarjeta en la que se hace constar las visitas sanitarias (Corbin, 1982: 55).

Para satisfacer los deseos de los clientes, las prostitutas tienen que poseer características diferentes. Se busca que todos los clientes potenciales encuentren su tipo femenino. En la casa Tellier, las cinco pueden atraer a toda clase de hombres. En la descripción de las cinco filles à numéro algunos aspectos realistas sobresalen que son eliminados en la película. Fernande no es "casi obesa" en el film. En realidad, el texto literario da cuenta de la afirmación de Parent-Duchâtelet (1981: 129), que sostiene en su estudio de campo, después de constatación, que la femme grasse abunda en los burdeles. Piensa que la vida ociosa y su voracidad son las causas principales.

Seguimos aquí a Laure Adler (1990: 57).

15 La prefectura de policía elabora normas eficaces y precisas para controlar el amor venal en los burdeles, desde el registro de las filles hasta la organización del burdel incluidas las visitas sanitarias. Entendemos mejor el juego de palabras que M.Tourneveau hace en La Maison Tellier al comentar que sólo podía ir los sábados por securitas causa, disait-il, faisant allusion à une mesure de police sanitaire dont le docteur Borde, son ami, lui avait révélé les périodiques retours (Maupassant, 1983: 22).

16 La Maison Tellier tendrá en el farolillo de la puerta de Le Plaisir el 3, insinuando la Trinidad. 
La gran cantidad de baños calientes y la alimentación copiosa hacen el resto ${ }^{17}$. No se preocupan del futuro y eso les empuja a comer constantemente. Su horario hace que duerman buena parte del día, la falta de trabajo físico también interviene directamente en su mollesse. Se pregunta si cualquier animal llevara tal vida, ¿no engordaría también? Las que están delgadas lo están por su constitución, influyendo también el hecho de que al no ser felices algunas no se procuran toda la comida que necesitan. Algunos guiños introdujo Max Opuhls a propósito de Fernande. Así, por ejemplo, en la secuencia inicial de la descripción de la casa cena mientras se ocupa de sus clientes. Igualmente, en el tren ella es la única que bebe y come mientras escucha la conversación de sus compañeras. Por otra parte, si la adaptación hubiera elegido a una Fernande a la que le escaseara el pelo, el efecto de mujer ideal del campo habría desaparecido.

Raphaëlle está lejos de ser una roulure de los puertos. Es presentada con mucha elegancia en el film. La descripción de su ojo derecho como si tuviera una mancha de tinta nos revela algo importante de su personalidad. Pascaline Mourier-Casile (1991: 25-26) parte de una declaración de Maupassant: 'Les femmes! J'aime mieux des sangsues. Je trouve décidément bien monotones les organes à plaisir, ces trous malpropres dont la seule fonction consiste à remplir les fosses d'aisance et à suffoquer les fosses nasales". La mujer no satisface al escritor normando, sólo lo hace la fille. El ojo de Raphaële tiene su explicación en dos textos superpuestos. El primero es $L$ 'inconnue donde se dice que la mirada de este tipo de ojo deja sobre la piel: "Une sorte de glu, comme s'il eût projeté sur les gens un de ces liquides dont se servent les pieuvres pour obscurcir l'eau et endormir leurs proies". En el segundo, Un soir, un pescador machaca con puntas afiladas un pulpo. El animal con "grande loque de chair rouge qui palpitait, corps musculeux et mou, se réfugie, crevé et mutilé pour mourir dans un trou plein d'eau saumâtre". La continuación del relato muestra que el pulpo es una metáfora de su mujer adúltera a la que no tiene la valentía de matar. El pulpo es la imagen del ojo que a su vez es el sexo. Pascaline concluye: 'L'oeiltrou-pieuvre et le trou-sexe se superposent". Raphaëlle pierde todas esas connotaciones en la película, su ojo derecho nos pasa desapercibido.

Rosa es la más alejada en la versión cinematográfica, ya que su descripción parecida a una ardilla y sus piernas minúsculas no coinciden en absoluto, además de que su participación es mayor que la de sus compañeras. Joseph se siente rápidamente atraído por ella. Canta, asimismo, con una voix eraillée. En el estudio efectuado por Parent-Duchâtelet, éste indica que la voz ronca es una particularidad de algunas prostitutas. Por su parte, Alain Corbin (1982: 25) explica que "provient probablement davantage de l'origine sociale, de l'abus de l'alcool et des longs séjours au froid que de la pratique du coït ab ore, comme le voulait le préjugé populaire". Por el contrario, en la adaptación, Rosa cuenta con otro físico muy distinto. También el carácter y comportamiento que los naturalistas podían deducir no se ve reflejado para nada. El protagonismo que tiene a lo largo de toda la película, sobre todo para resaltar mejor la relación de complicidad que se establece con Joseph, es una diferencia importante.

Flora no es coja sino que se cantonea cuando anda. Las dos destinadas a la planta baja no se les apoda irónicamente las deux Pompes, aludiendo a la cantidad de alco-

17 "De toutes les passions, la seule vraiment respectable me parait être la gourmandise" Guy de Maupassant, Amoureux et primeurs. 
hol que tomaban con los clientes. Ophuls lo salvará con: elles touchaient à la consommation. Louise compartirá la inocencia infantil y la simplicidad de un ser sin malicia.

Hay varias características que comparten las cinco y que se manifiestan de manera casi pareja en las dos versiones. Laure Adler (1990: 99) menciona la infancia psicológica en la que viven las prostitutas, sin llegar nunca a la madurez:

Tout d'abord la prostituée est une enfant. Jamais elle ne parviendra à maturité. Elle apparaît comme une ébauche de femme, une femme pas terminée. L'enfant, le fou, le sauvage! De ces trois figures elle capte les principales caractéristiques: l'immaturité de l'enfance, l'instabilité de la folie, l'insouciance du sauvage.

La inmadurez parece ser una evidencia para probar que ellas no siguen el desarrollo normal de la psicología humana en una sociedad racional. Dicho comportamiento se debe al aislamiento y a la alineación a las que se les somete. En el tren el viajante las hace reír con los patos de los campesinos. Este episodio muestra el lado infantil, pero también hay un mensaje subyacente. Esta escena de juego con los patos nos lleva a pensar que esas malheureuses bêtes son en cierta manera las prostitutas. Los patos sufren el mismo trato que ellas en el burdel, mientras éstos están en una prison d'osier cuando se les acaricia, las filles lo están en un prostíbulo. Si ellas consideran a los animales como juguetes, los hombres harán lo mismo con ellas. Prostitutas y patos comparten un mismo encierro.

Como seres infantiles por excelencia que son, tienen un apego especial a los niños; nada más ver a Constance

toutes les femmes la voulaient caresser, avec ce besoin d'expansion tendre, cette habitude professionnelle de chatteries, qui, dans le wagon, les avait fait toutes embrasser les canards. Chacune l'assit sur les genoux, mania ses fins cheveux blonds, la serra dans les bras en des élans d'affection véhémente et spontanée" (Maupassant 1983: 32).

Rosa lleva a su cama a Constance para que no tenga miedo, por eso y porque es también la hija que toda prostituta desea tener.

Las prostitutas de la novela se presentan como seres auténticos, catalizadoras para unos hombres a los que divierten y satisfacen. Las prostitutas son agentes de un mundo de doble moral, con los valores construidos de manera hipócrita. Son mujeres que poseen grandes virtudes frente a la burguesía, víctima de sus propios valores. Conviene señalar, sin embargo, que la burguesía va en búsqueda del amor que no puede alcanzar en la vida conyugal. El amor es un instinto que Dios implanta en los hombres, de ahí su fortaleza frente al matrimonio cuyo origen humano lo pone en desventaja. De los trescientos cuentos escritos por el normando, más sus novelas, sólo encontramos cuatro casos de mujeres fieles a sus maridos (Mourier-Casile, 1991: Au fil du texte, IV): Jeanne Lamare- "Une vie"; la heroína de las "Caresses"; la de "Un échec" y Germaine en "L'Angelus". Sin embargo, seis son las razones por las que las mujeres engañan a sus maridos (Gaudefroy-Demombynes,1943: 120): la enfermedad del esposo -"Un coq chanta"-; su fealdad -"Les Épingles"-; su brutalidad y necedad -Pierre et Jean-; su infidelidad -La paix du ménage-; su incapacidad para satisfacerla-Mont-Oriol-. El amor se confunde en buena medida con el deseo 
por lo que tratarlo en literatura implica pasar por el microscopio el abanico de comportamientos de la psique. El deseo bajo distintos enfoques es, en suma, el tema por excelencia que trata Max Ophuls en la adaptación de dos cuentos y una novela corta. El placer como lucha contra la vejez - "Le Masque"-, el deseo irrefrenable como instinto catalizador -“La Maison Tellier"- y el placer como la muerte en vida -"Le Modèle"-. Maupassant se mofaba del amor de los poetas, en especial los clásicos, a los que tildaba de amar sin ideal, de forma irrealizable y sobrehumana. Pensaba que eran quizá los únicos que nunca habían amado de verdad a ninguna mujer de carne y hueso, por lo que esa falta les incapacitaba a desentrañar el alma femenina. Si las leyes de los hombres formaban una barrera infranqueable para que el amor se diera en la pareja, sólo era posible éste fuera de ella. La prostituta es la impulsión hasta convertirse en eros y thánatos de unos burgueses cuya única salida de realización amorosa era desearla y poseerla.

La casa Tellier en las dos versiones es el mejor ejemplo de eros como instinto de vida. Thánatos sale a escena en momentos de ausencia o vacío. El sábado los burgueses sienten la "pulsión de la muerte" al encontrar el prostíbulo cerrado. $\mathrm{Su}$ frustración acaba en pelea al ser incapaces de mantener una conversación sin herir a sus interlocutores. Las prostitutas y la hija del carpintero, la misma noche, no consiguen conciliar el sueño. Todo el "regimiento Tellier" llora y hace llorar a todos los presentes en la ceremonia. Joseph, bajo los efectos del alcohol, intenta violentar a Madame Rosa tras el banquete. Joseph corre tras el tren en un intento desesperado de no perderla. No obstante, cuando la trama finaliza y todo vuelve a su lugar, eros restablece el orden en su alegre cotidianeidad. No puede ser siempre fiesta. Pero al mismo tiempo se construyen como espejos del propio hombre. En ninguna de las dos versiones, aparece el tipo de prostituta como una amenaza, más bien al contrario, como capaz de restablecer el orden de la rutina burguesa. Tampoco existe ninguna toma de posición por parte de los narradores, no se les juzga ni desprecia. No hay juicios de valor existentes a modo de Zola, no aparece ni un discurso de indignación ni de moralizador, sino un fino distanciamiento de los personajes que a veces se entiende como juego irónico. La visión misógina que se atribuye a menudo a Maupassant desaparece aquí -en Max Ophuls todavía mucho más-. El escritor se presenta como un amigo de las mujeres aquí. Al contrario de otros escritores podemos afirmar que posee una misoginia moderada. No trata a la prostituta como un ser aparte sino que le da íntegramente su papel de mujer, una mujer moderna en cierto sentido. Noëlle Benhamou (1997: 257) defiende una idea que nos es muy querida y que compartimos completamente: "Maupassant a décrit les prostituées en homme du monde". Por fin, la eliminación de toda crudeza en las acciones y en la forma de narrar, sugieren un naturalismo depurado en el escritor normando y su desaparición en el film.

\section{Conclusión}

Los realizadores de la Nouvelle Vague admirarán a Max Ophuls, sobre todo por sus últimas obras. Una de las razones de esta admiración se explica por la mirada interpuesta de un narrador que cuenta parte del relato, una mirada desde el interior pero alejada de los personajes. Sabemos que Maupassant había bebido de la escuela de la mirada de Flaubert, sin seguir demasiado su método. Tampoco era un asiduo del es- 
tilo indirecto libre por lo que se podría considerar que el ethos de Maupassant ophulsiano sería una moderna propuesta cinematográfica del DIL, una unión entre el DIL y el cinéma de voyant. Esta mirada interpuesta no es sólo un punto de vista muy especial sino que lo es porque la recorre el movimiento como principio motor. "La vie, pour moi, c'est le mouvement", dice Lola Montès de viaje en una de las escenas del inicio. Por último, no sería descabellado considerar que lo que tanto atrajo a Truffaut del director franco-alemán fuera su depuración naturalista de los personajes así como el manejo del movimiento de la cámara.

\section{Referencias bibliográficas}

Adam, J. M., (2008) La linguistique textuelle. Introduction à l'analyse textuelle des discours. París, A. Colin, 2a edición revisada.

Adler, L., (1990) Les Maisons closes 1830-1930. París, Hachette, coll. Littératures.

Benhamou, N., (1997) Filles, prostituées et courtisanes dans l'œuvre de Guy de Maupassant. Lille, Presses Universitaries du Septentrion.

Berthomé, J.P., (1997) Le Plaisir. París, Nathan.

Bazin, A., (1952) "Le Plaisir de Max Ophüls" in France-Observateur. No 95, 6 de marzo, p. 25.

Bury, M., (1994) La Poétique de Maupassant. París, SEDES.

Corbin, A., (1980) La prostituée. Misérable et glorieuse la femme du XIXe siècle. París, Fayard.

Corbin, A., (1982) Les Filles de noce: misère sexuelle et prostitution (XIX`e siècle). París, Flammarion.

Dahhan, Ph., (1996) Guy de Maupassant et les femmes. Essai, Luneray, Editions Bertout, coll. La mémoire normande.

Del Prado, J., Bravo Castillo, J. \& M. Picazo, (1994) Autobiografia y modernidad literaria. Cuenca, Universidad de Castilla-La Mancha.

Del Prado, J., (1994) Historia de la literatura francesa. Madrid, Cátedra. Edición de 2009.

Foucault, M., (1997) Histoire de la sexualité I: la volonté de savoir. París, Gallimard.

Gaudefroy-Demombynes, L., (1943) La femme dans l'oeuvre de Maupassant. París, Editions Du Mercure De France.

Genette, G., (1972) Figures III. París, Le Seuil.

Godard, J.L, (1958) "Retrospective Ophüls" in Cahiers du cinéma. No 81, marzo.

Lutanie, J.C., (1993) Une lecture paranoïaque-critique de La Maison Tellier de Guy de Maupassant. París, Le Veilleur Éditeur.

Maingueneau, D., (2004) Le discours littéraire. París, A. Colin.

Maupassant, G. de, (1973) Correspondance. Evreux, Éd. Jacques Suffel, Le Cercle du Bibliophile, t. I.

Maupassant, G. de, (1974) Contes et nouvelles I. París, éd. Louis Forestier, París, Gallimard, coll. "Bibliothèque de la Pléiade".

Maupassant, G. de, (1979) Contes et nouvelles II. París, éd. Louis Forestier, París, Gallimard. coll. "Bibliothèque de la Pléiade".

Maupassant, G. de, (1983) La Maison Tellier. París, Edición de Patrick Wald Lasowski, Albin Michel.

Maupassant, G. de, (2006) Lettres intimes, une collection dévoilée. Éd. Anne-Marie Springer, Les Éditions Textuel. 
Meiroz, J., (2009) “Ce que l'on fait dire au silence, posture, ethos, image d'auteur” in Argumentation et Analyse du discours [En línea]. No 3. Disponible en: http//aad.revues.org/667 [Último acceso el 12 de abril de 2018].

Mourier-Casile, P., (1991) Guy de Maupassant. La Maison Tellier. París, Pocket. Ophuls, M., (1952) Le Plaisir. París, Gaumont. Edición masterizada 2009.

Ophuls, M., (1962) "Souvenirs" in Cahiers de cinéma. París, n 133, julio, p.30. Parent-Duchâtelet, A., (1981) La Prostitution dans la ville de Paris. París, Seuil. Todorov, T., (1978) Les genres du discours. París, Éditions du Seuil. 